\title{
Determination of Water-Yield Basil Function under Deficit Irrigation Conditions and Use of Nano Fertilizer
}

\section{MOHAMMAD NADERIANFAR ${ }^{* 1}$, MAJID AZIZI ${ }^{2}$, SHAPOUR KOOHESTANI $^{3}$}

\begin{abstract}
Basil (Ocimum basilicum L.) is one of the important aromatic plants belonging to the family Lamiaceae, which is used as an herb, spice as well as fresh vegetable.The present study was performed to determine the irrigation depth index under different management conditions with evaluating the effect of deficit irrigation, soil texture and nano fertilization on basil. The experiment was performed as a factorial based on randomized complete block design (RCBD) with 18 treatments and three replications at weather station, Ferdowsi University of Mashhad. Deficit irrigation treatments consisted of three levels of irrigation $\left(\mathrm{I}_{1}=100 \% \mathrm{ET}_{\mathrm{c}}\right),\left(\mathrm{I}_{2}=75 \% \mathrm{ET}_{\mathrm{c}}\right),\left(\mathrm{I}_{3}=50 \% \mathrm{ET}_{\mathrm{c}}\right)$ and three levels of nano fertilizers, containing nano fertilizer with full concentration $\left(\mathrm{F}_{1}\right), 70 \%\left(\mathrm{~F}_{2}\right)$, and nonusing of nano fertilizer $\left(\mathrm{F}_{3}\right)$ were implemented in two light soil texture $\left(\mathrm{S}_{1}\right)$ and medium soil texture $\left(\mathrm{S}_{2}\right)$. The results showed that the average actual evapotranspiration estimation by REC-P55 device has been equal to $3.38 \mathrm{~mm}$ at the beginning of the growing period of basil, which amount has increased to $8.60 \mathrm{~mm}$ during basil development in the middle of growth period. The results of crop coefficient analysis showed that the maximum $\mathrm{kc}$ of basil (1.42) was detected in July. The results also indicated that the highest water use efficiency (WUE) was obtained in terms of fresh and dry herb yield as 2.06 and $0.37 \mathrm{~kg} / \mathrm{m}^{3}$ in $\mathrm{S}_{2} \mathrm{I}_{3} \mathrm{~F}_{3}$ treatment, respectively, while the maximum water use efficiency in terms of seed yield $\left(0.37 \mathrm{~kg} / \mathrm{m}^{3}\right)$ was obtained in $\mathrm{S}_{1} \mathrm{I}_{2} \mathrm{~F}_{2}$ treatment. Using the research results, according to different levels of water use of functions of yield $Y(w)$, cost $C(w)$, and benefit $B(w)$ for basil based on mathematical and economic analysis of these functions, irrigation index and optimal irrigation depths were evaluated. It was found that with deficit irrigation under water restriction conditions, with the aim of maximum use of water volume unit, the optimal water consumption depth will be reduced by $20 \%$ compared to maximum irrigation mode. Also, with this amount of deficit irrigation, the maximum Rial return per cubic meter of water consumption would be as 1849 Rials.
\end{abstract}

Keywords: nano-fertilizer, deficit irrigation, yield function, optimum irrigation depth

\footnotetext{
* Corresponding author. Email: Naderian.mohamad@yahoo.com

${ }^{1}$ Assistant Professor, Water Engineering Department, University of Jiroft, Kerman Iran

2Professor, Horticultural Science Department, Ferdowsi University of Mashhad, Mashhad - Iran

${ }^{3}$ Assistant Professor, Water Engineering Department, University of Jiroft, Kerman Iran
}

1786-335X @ 2017 Akadémiai Kiadó, Budapes 


\section{Introduction}

Deficit irrigation is a strategy for growing crops under water scarcity; however, it leads to yield reduction per unit area. From the farmer's perspective, the optimal strategy is generally to use a volume of irrigation water maximizing net profit and not the amount of water producing the maximum yield. Deficit irrigation is an optimal strategy in which plants are consciously allowed to reduce yield by receiving less water than is required (English et al., 1990). Deficit irrigation is one of the methods to maximize the irrigation water use efficiency (IWUE) per unit of applied water. In this method, the crop is exposed to a certain level of water stress either at a different particular stage or throughout the growing season (English and Raja, 1996).

In recent years, many studies have been done about the effect of deficit irrigation and water stress on WUE and yield components of basil (De souza et al, 2005; Khalid, 2006; Fereres and Soriano, 2007; Ekren et al, 2012).The result of Ekran et al. (2012), showed that water stress negatively affected the plant height and the yields of purple basil. Also the IWUE were not significant according to different levels of water irrigation. The result of Unlu et al. (2011), in a 4-year study on the yield and yield components of drip irrigated cotton showed that seed yield was significantly affected by deficit irrigation. Deficit irrigation significantly affected crop yield and all yield components considered in this study. The average irrigation water use efficiency (IWUE) was between $9.5 \mathrm{~kg} / \mathrm{ha} / \mathrm{mm}\left(\mathrm{I}_{100}\right)$ and $14 \mathrm{~kg} / \mathrm{ha} / \mathrm{mm}$ $\left(\mathrm{DI}_{50}\right)$. The results obtained from the $\mathrm{DI}_{70}$ treatment (irrigation applied at $70 \%$ of full irrigation) could be used as a good alternative in semiarid regions under limited irrigation water supplies. Under this condition, water savings of $22 \%$ were obtained with only $11 \%$ yield loss. Garcia-Vila and Fereresa (2012) combined the AquaCrop model with an economic model for the optimization of irrigation management at farm level. They used the AquaCrop dynamic model to stimulate alternative crop responses to different irrigation strategies as inputs to their economic optimization model. The application of the model to the study area showed that the current changes in cropping patterns were induced by the policies encouraging water savings and the increase in water prices has played no role. The model predicted a strong negative impact on farm income of delaying a decision on the level of seasonal water allocation by the water authority, reaching up to $300 € /$ ha. English and Raja (1996) analyzed deficit irrigation in 3 quite different situations to understand the potential benefits and risks associated with such different irrigation strategy. The results 
showed that deficits between 15 and 59 percentage would be economically optimal, depending on the circumstances, and the estimated margin is quite wide for error in these estimates. The results of Hassan and Ali (2014) research showed that the vegetative growth parameters improved as a result of applying higher irrigation levels compared to lower levels. Irrigation water use efficiency was increased by reducing the irrigation levels. English et al. (1990), conducted some studies on winter wheat in different farms. The mathematical functions '(water use-yield)' and '(water use-costs)' were determined in their study and water use optimization amount was calculated regarding two conditions: water resource limitations and land limitations. The result of Tavakoli and Moghadam (2012) showed that with $66 \%$ of full irrigation and use of 90 kg.N.ha-1 , combined with appropriate management, wheat output could be substantially increased in the semiarid climate zone. Water stress negatively affected the height and yields of basil. On the contrary, the essential oil percentage of the plant increased as the applied amount of irrigation water decreased. Water stress also had a positive effect on essential oil composition of the plant (Bettaieb et al., 2009; Ekren et al., 2012). The results of Omobolanle Ade-Ademilua et al.'s (2014) research on the growth and essential oil yield of African basil showed that water stress only was observed in plants grown in full sunlight. Their results demonstrated that African basil will produce relatively high essential oil yields per plant when grown under natural shade, irrespective of water stress and despite poor vegetative growth.

Since little research has been done in relation to the water production function-yield and water use efficiency in basil, the present study was conducted to determine actual evapotranspiration, crop coefficients, production function, water use efficiency and irrigation depth index of basil under the influence of soil texture, nano fertilizer and deficit irrigation.

\section{Materials and Methods}

Seeds planting in two consecutive years was done on 17 June 2013 in the first year and 7 May 2014 in the second year for better results. In this paper, we used the second year data. In the weather station of Agriculture College, Ferdowsi University of Mashhad (FUM). To investigate the effects of deficit irrigation, fertilizer, and soil texture on growth and yield of basil (Ocimum basilicum L.), a factorial experiment based on randomized complete block design (RCBD) with 18 treatments and three replications was conducted. 
Irrigation treatments included three irrigation levels $I_{1}=100 \% E t_{c}$, $I_{2}=75 \% E t_{c}$ and $I_{3}=50 \% E t_{c}$. The water source for irrigation was supplied from greenhouse at Ferdowsi University of Mashhad (FUM), some of the water chemical properties are shown in Table 1. Up to one month after planting (6-8 leaf stage seedling), the pots were irrigated by equal amounts of water, and then, deficit irrigation treatments have been applied. Fertilizer treatments consisted of three levels, including a level as controls $\left(\mathrm{F}_{3}\right)$. Also, the first fertigation was done on 3 July 2013 (15 days after planting). Plastic pot was used for basil cultivation embedded in the floor drain. In each pot, 15 basil seeds were planted at $1 \mathrm{~cm}$ of soil depth, and after germination, five seedlings were held in each pot. The pot size was 17.2 liters $(27 \mathrm{~cm}$ diameter and $30 \mathrm{~cm}$ height).

Table 1. Chemical properties of water irrigation

\begin{tabular}{|c|c|c|c|c|c|c|c|c|}
\hline $\mathrm{EC}$ & $\mathrm{pH}$ & $\mathrm{Na}$ & $\mathrm{Ca}^{2+}$ & $\mathrm{CO}_{3}{ }^{2-}$ & $\mathrm{HCO}_{3}{ }^{-}$ & $\mathrm{Cl}^{-}$ & $\mathrm{Mg}^{2+}$ & SAR \\
\hline$\left(\mathrm{dS} \mathrm{m}^{-1}\right)$ & - & & & (meq/ & 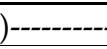 & & & $(\text { meq/1) })^{1 / 2}$ \\
\hline 1.23 & 8.2 & 5 & 3 & 0.32 & 5.01 & 6.47 & 3.8 & 2.71 \\
\hline
\end{tabular}

Two soil types, namely as sandy $\left(\mathrm{S}_{1}\right)$ and sandy loam $\left(\mathrm{S}_{2}\right)$, were prepared manually. The textures were determined based on hydrometer methods in the soil laboratory of Agriculture College of FUM. Physical and chemical properties of the soil are presented in Table 2.

Table 2. Physical and chemical properties of soil

\begin{tabular}{|c|c|c|c|c|c|c|c|c|}
\hline Mark & Soil texture & $\theta_{f c}(\%)$ & $\begin{array}{c}\rho_{b} \\
\left(\mathrm{~g} \mathrm{~cm}^{-3}\right)\end{array}$ & $\begin{array}{c}\mathrm{N} \\
\left(\mathrm{mg} \mathrm{kg}^{-1}\right)\end{array}$ & $\begin{array}{c}\mathrm{P} \\
\left(\mathrm{mg} \mathrm{kg}^{-1}\right)\end{array}$ & $\begin{array}{c}\mathrm{K} \\
\left(\mathrm{mg} \mathrm{kg}^{-1}\right)\end{array}$ & $\mathrm{pH}$ & $\begin{array}{c}\mathrm{CCE} \\
(\%)\end{array}$ \\
\hline $\mathrm{S}_{1}$ & Sandy & 13 & 1.42 & 511 & 4.9 & 105.3 & 8.01 & 8.9 \\
\hline $\mathrm{S}_{2}$ & Sandy loam & 16 & 1.53 & 508 & 4.8 & 108.6 & 7.85 & 8.1 \\
\hline
\end{tabular}

We determined irrigation depth, soil moisture at field capacity (FC) and permanent wilting point (PWP) using pressure plates. Class-A pan evaporation was used for irrigation treatments at every irrigation time. The amount of used water was calculated by considering the pan coefficient (0.80) and the proposed FAO crop coefficient (Allen et al, 1998). The water irrigation volume was calculated during the growth period $\left(E T_{c}=k_{c} k_{p} E_{p a n}\right)$, and irrigation was applied to the graduated cylinder by considering the pot area. It should be mentioned that the rainfall did not occur during the testing period. Basil coefficient was considered in the early stages of 
development, growth, middle and end as 0.6, 1, 1.15 and 1.1, respectively (Allen et al, 1998), and the growing season was in each stage during 16, 44, 32 and 18 days. Also, the actual evapotranspiration of basil, soil moisture were measured by using the REC-P55 ${ }^{1}$. REC-P55 device, consisting of two parts: data logger and sensors. Thirty six sensors were used for measuring soil moisture in two replications. For calibration of REC-P55 device, two pots with $S_{1}$ and $S_{2}$ soil texture were used. The pots were saturated with water, and then, the weight of the pot was measured on different days to achieve the initial weight of the dry soil through reading the sensors. By measuring the weights of dry soil and wet soil, the soil moisture content was calculated and the equation between volumetric moisture and sensor readings was obtained. In this way, the sensors were calibrated. According to the soil texture and the maximum evapotranspiration, irrigation was considered in two days and constant during the growing season. Soil moisture was measured before and after each irrigation and following the stop of drainage with REC-P55, and the amount of water used for each irrigation treatment during the growing season was calculated.

Fertilizer ${ }^{2}$ program was applied at the beginning of the growing season, using the phosphorus fertilizer, Super micro (including 11 main element needed by plants in the form of liquid capable of available ion), potassium and nitrogen at a concentration of $100 \%\left(\mathrm{~F}_{1}\right)$ and $70 \%\left(\mathrm{~F}_{2}\right)$ and without fertilizer $\left(F_{3}\right)$ based on the soil chemical properties (Table 2 ) according to the recommendations by the fertilizer manufacturer. Analysis of fertilizer (\% of different elements) showed that phosphorus chelated fertilizer contains $18 \%$ available phosphorus ions (Table 3), while chelate potassium and nitrogen are absorbed with 23 and 25 percent ions. The fertilizer consumption is provided at every stage of cultivation in Table 4 in liters per hectare. Thus, the consumption involve a total of $18 \mathrm{~L} /$ ha fertilizer, 40 percent in the early and mid-growing season and 20 percent at the end of the growing season. The experimental data were statistically analyzed using Minitab15 software and an analysis of variance (ANOVA) was performed. The means were compared using the revised L.S.D. test at 0.05 levels.

\footnotetext{
${ }^{1}$ The REC-P55 was invention by Dr. Hossein Ansari, faculty member of Ferdowsi University of Mashhad

${ }^{2}$ The Nano fertilizers used in this research were produced by Sepehr Parmis Company
} 
Table 3.The different percentage of chemical fertilizers elements

\begin{tabular}{|c|c|c|c|c|c|c|c|c|c|c|c|}
\hline Fertilizer type & $\mathrm{N}$ & $\mathrm{P}$ & $\mathrm{K}$ & $\mathrm{Fe}$ & $\mathrm{Zn}$ & $\mathrm{Mn}$ & $\mathrm{Mg}$ & $\mathrm{Ca}$ & $\mathrm{Cu}$ & $\mathrm{Mo}$ & $\mathrm{B}$ \\
\hline Super micro & 5 & 4 & 2 & 4 & 5 & 2 & 1 & 15 & 1 & 0.04 & 0.06 \\
\hline$(\mathrm{N})$ & 25 & - & - & - & - & - & - & - & - & - & - \\
\hline$(\mathrm{P})$ & - & 18 & - & - & - & - & - & - & - & - & - \\
\hline$(\mathrm{K})$ & - & - & 23 & - & - & - & - & - & - & - & - \\
\hline
\end{tabular}

Table 4. The amount of nano fertilizer scheduled for the beginning of the growing season

\begin{tabular}{|c|c|c|c|c|c|}
\hline \multicolumn{2}{|c|}{ Fertilizer type } & $\mathrm{N}$ & $\mathrm{P}$ & $\mathrm{K}$ & Super micro \\
\hline \multicolumn{2}{|c|}{ Concentration (L/ha) } & 11 & 7 & 7 & 7 \\
\hline \multicolumn{2}{|c|}{$\mathrm{A}^{*}\left(\mathrm{~m}^{2}\right)$} & 0.0572 & 0.0572 & 0.0572 & 0.0572 \\
\hline \multicolumn{2}{|c|}{$\mathrm{Q}^{* *}(\mathrm{~mL})$} & 0.063 & 0.04 & 0.04 & 0.04 \\
\hline \multicolumn{2}{|c|}{ Error } & $20 \%$ & $20 \%$ & $20 \%$ & $20 \%$ \\
\hline $\mathrm{F}_{1}(\mathrm{~mL})$ & $(100 \%)$ & 0.075 & 0.05 & 0.05 & 0.05 \\
\hline $\mathrm{F}_{2}(\mathrm{~mL})$ & $(70 \%)$ & 0.053 & 0.035 & 0.035 & 0.035 \\
\hline
\end{tabular}

$\mathrm{A}^{*}$ : Cross section of pots

$\mathrm{Q}^{* *}$ : The volume of nano fertilizer

\subsection{Actual evapotranspiration}

Evapotranspiration can also be determined by measuring the various components of the soil water balance (Allen et al, 1998).

$$
\mathrm{ET}=\mathrm{I}+\mathrm{P}-\mathrm{RO}-\mathrm{DP} \pm \Delta \mathrm{S}
$$

Where, Irrigation (I) and rainfall (P) add water to the root zone. Part of I and $P$ might be lost by surface runoff (RO) and by deep percolation (DP) that will eventually recharge the water table. If all fluxes other than evapotranspiration (ET) can be assessed, the evapotranspiration can be deduced from the change in soil water content $(\Delta S)$ over the time period. 
In the crop coefficient approach, the crop evapotranspiration, $E T_{c}$, is calculated by multiplying the reference crop evapotranspiration, $E T_{o}$, by a crop coefficient, kc (Allen et al, 1998):

$$
k c=\frac{E T_{c}}{E T_{o}(\text { PMF or Pan })}
$$

Where, $E T_{c}$ : crop evapotranspiration $\left[\mathrm{mm} \mathrm{d}^{-1}\right], k c$ : crop coefficient [dimensionless],

$E T_{0}$ : reference crop evapotranspiration $\left[\mathrm{mm} \mathrm{d}^{-1}\right]$.

\subsection{FAO's equation}

The crop yield response factor $\left(k_{y}\right)$ gives indication of whether the crop is tolerant of deficit irrigation. Crop yield response data from deficit irrigation were fitted to linear equation used earlier by Doorenbos and Kassam (1979):

$$
1-\frac{Y_{a}}{Y_{m}}=k_{y}\left(1-\frac{E T_{a}}{E T_{m}}\right)
$$

Where, $Y_{a}$ and $Y_{m}$ is actual and maximum yield. $E T_{a}$ and $E T_{m}$ is actual and maximum evapotranspiration respectively.1- $Y_{a} \Upsilon_{m}$ is the relative crop yield decrease and $1-E T_{a} / E T_{m}$ is the relative evapotranspiration deficit. Crops with higher $k_{y}$ are more sensitive to water deficit.

\subsection{Optimal levels of water use}

English (1990) has derived equations for each of the application levels described above. The first equations presented in the original paper are completely general. The specific forms of those equations depend upon the forms of the cost and production functions that are utilized. For the particular case of a quadratic production function and linear cost function of the form:

$$
\begin{gathered}
Y(w)=a_{1}+b_{1} w+c_{1} w^{2} \\
C(w)=a_{2}+b_{2} w
\end{gathered}
$$

where: $Y(w)$ production function, $C(w)$ cost function, $a_{1}, b_{1}, c_{1}, a_{2}$ and $b_{2}$ is production and cost function coefficients of the form. 
(a): for the yield maximizing level of water use, $W_{m}$ :

$$
W_{m}=-\frac{b_{1}}{2 c_{1}}
$$

(b): for the profit maximizing level when land is the limiting resource, $W_{l}$ :

$$
W_{1}=-\frac{b_{2}-b_{1} P}{2 c_{1} P}
$$

where: $P$ is product price (per kilogram)

(c): for the profit maximizing level when water is the limiting resource, $W_{w}$ :

$$
W_{w}=\left[\frac{a_{1} P-a_{2}}{c_{1} P}\right]^{0.5}
$$

(d): for the level of deficit irrigation at which net income will equal that at full irrigation when land is limiting, $W_{\mathrm{el}}$ :

$$
W_{e l}=\frac{\left(b_{2}-b_{1} P\right) \pm Z_{1}}{2 c_{1} P}
$$

where

$$
Z_{1}=\left[\left(b_{1} P-b_{2}\right)^{2}-4 c_{1} P\left(\frac{b_{1}^{2} P}{4 c_{1}}-\frac{b_{1} b_{2}}{2 c_{1}}\right)\right]^{0.5}
$$

(e): for the level of deficit irrigation at which net income will equal that at full irrigation when water is limiting, $W_{e w}$ :

$$
W_{e w}=\frac{-Z_{2} \pm\left[Z_{2}^{2}-4 c_{1} P\left(a_{1} P-a_{2}\right)\right]^{0.5}}{2 c_{1} P}
$$

where:

$$
Z_{2}=\frac{b_{1}^{2} P+4 a_{1} c_{1} P-4 a_{2} c_{1}}{2 b_{1}}
$$

In this study, the price per liter of nano potassium, nitrogen, phosphorus and supermicro are based on prices nano fertilizer Distribution Company in 2014 year, respectively 165000, 110000, 185000 and 240000 Rials, which was considered as fixed costs. The variable cost for each cubic 
meter of water was considered, according to the Energy Department in Agriculture sector 850 Rial (Ansari et al., 2014).

The price of one kilogram of fresh vegetables and basil seeds were estimated according to Agriculture Organization of Khorasan Razavi, 5,000 and 80,000 Rials ${ }^{3}$, respectively.

\section{Results and Discussion}

\subsection{Actual evapotranspiration}

The results of the daily changes of basil actual evapotranspiration on water balance method are shown in Figure 1(a). The evapotranspiration graph of basil, as expected, was an upward trend, fixed and declining, which is indicative of different growth stages. This phenomenon can be explained at the beginning of the growing season (early growth stage). Due to the small size of the leaves, the evapotranspiration is minimum, and with plant growth and increased leaf area, the evapotranspiration will decrease at the end of the growing season. Maximum evapotranspiration as $9.6 \mathrm{~mm}$ occurs after 83 days from date of cultivation in August. The results of Chatrnoor et al (2011) study on the water requirement and crop coefficient of basil in Iran-Ardabil showed that maximum evapotranspiration of basil is achieved at a rate of $9.31 \mathrm{~mm}$ in August. Since the study was conducted in arid and semiarid climate, the evapotranspiration was little more than reported in the research by Chatrnoor et al in Ardabil. At the beginning of the growing season, the average actual evapotranspiration of basil has been equal to 3.75 $\mathrm{mm}$, and by increasing the cultivation period, it increased at a rate of 8.28 $\mathrm{mm}$ in the middle period. Daily evapotranspiration of basil, in addition to increasing and decreasing trend, has been swinging repeat. The fluctuations in the time before the first harvest reached its peak and takes a downtrend after picking leaves. The ups and downs can be seen in the graph.

Basil daily evapotranspiration trend is shown in Figure 1(b) using the REC-P55. The results show that the highest evapotranspiration measurements were obtained by using the device as $12.7 \mathrm{~mm}$ after 63 days of cultivation in July. The average evapotranspiration measured by the device was $3.38 \mathrm{~mm}$ at the beginning of the growing season of basil. This cultivation period increased by increasing the amount of $8.60 \mathrm{~mm}$ in the middle period. Also, in Figure 1(b), fluctuations in evapotranspiration are well observed due to picking up during the culture of basil.

${ }^{3}$ One dollar $=32510$ Rials 


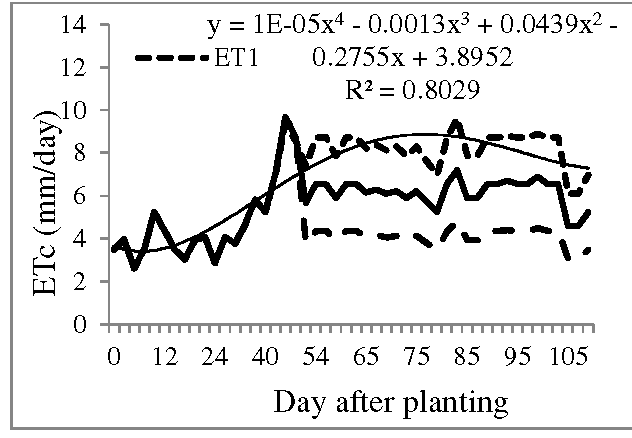

(a)



(b)

Figure 1. Daily changes of actual evapotranspiration basil:

a) water balance and b) REC-P55

\subsection{Crop coefficient}

Daily changes of basil factor in the irrigation treatments are in Figure 2(a) and $(b)$. Line equation fitted to the data showed that the crop coefficient was the lowest at the beginning of the growing season and by increasing the growing season, the crop coefficient value increased. Thus, the highest basil crop coefficient achieved as the amount of 1.42 in July. After calculating the reference evapotranspiration by using local meteorological data, to calculate evapotranspiration by water balance method during the growing season, a minor factor of basil $(\mathrm{kc})$ was calculated. By determining the duration of growth according to the FAO-56, the crop coefficients were calculated for each stage, shown in the Table 5. The crop coefficient in the initial, development, middle and late growth stages were estimated respectively as $0.48,1.05,1.1$ and 0.95 . Comparing the single crop coefficient measured and crop coefficient proposed by FAO-56 represents an acceptable proximity between the measured values and suggestions. The FAO recommends the measured value as 15\% lower in the third period (Allen et al, 1998).

Basil crop coefficient is allocated in the first month and the third month as minimum and maximum values (Table 5). The reason was its initial growth stage until the plant turns into multi leaves, which at this stage, due to the low level of plant and aerial, requires low water, and gradually with continual of vegetative growth and generative stages, the crop coefficient has increased. Finally, in the third month, which coincides with the flowering plant and photosynthesis, the respiration rate rises and 
reaches its maximum crop water demand that takes place in the harvest, and then reduces the crop coefficient. This is the reason for rise and fall of successive crop coefficient (Abedi Koupai et al, 2011).

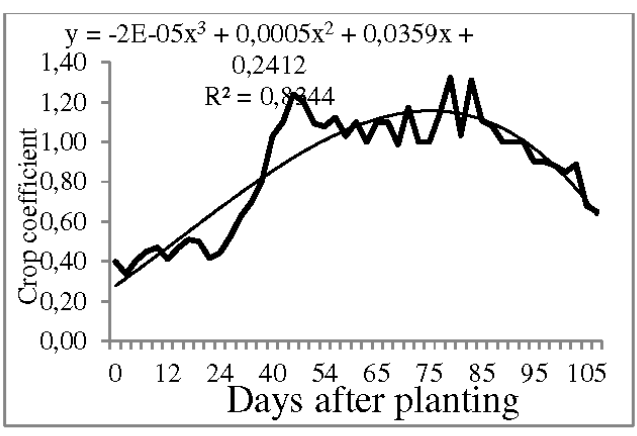

(a)

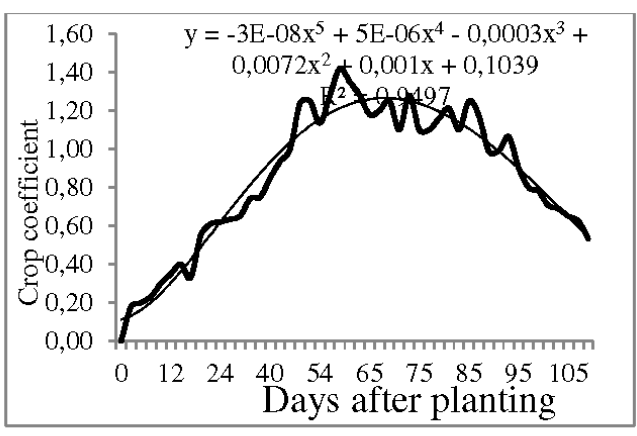

(b)

Figure 2. Changes crop coefficient during the growing season in the full irrigation treatment: a) water balance b) REC-P55

Table 5. Growth stages of basil in the full irrigation treatment and crop coefficient

\begin{tabular}{|c|c|c|c|c|}
\hline Day after planting & 30 & 60 & 90 & 110 \\
\hline During the period & 16 & 44 & 32 & 18 \\
\hline Crop coefficient (calculated) & 0.48 & 1.05 & 1.11 & 0.95 \\
\hline Crop coefficient (FAO-56) & 0.60 & - & 1.15 & 1.10 \\
\hline
\end{tabular}

\subsection{Water use efficiency (WUE)}

Results of statistical analysis on water use efficiency in terms of basil fresh leaves yield (WUE $\mathrm{wet}_{\text {) }}$ are provided in Table 6. The results show that irrigation and soil texture has a significant effect on water use efficiency so that it has become significant at the $0.01 \%$ level, while nano fertilizer treatment was significant at 0.05 level. The results of comparison of the interaction of three treatments (Table 7) showed that the maximum water 
Table 6. Analysis of variance (Mean squares) for the water use efficiency (WUE)

\begin{tabular}{|c|c|c|c|c|}
\hline Source of variation & $\mathrm{df}$ & $W U E_{\text {wet }}$ & $W U E_{\text {dry }}$ & $W U E_{\text {seed }}$ \\
\hline $\mathrm{S}$ & 1 & $1.03^{* *}$ & $0.032^{* *}$ & $0.013^{\mathrm{ns}}$ \\
\hline $\mathrm{I}$ & 2 & $0.33^{* *}$ & $0.017^{* *}$ & $0.008^{\mathrm{ns}}$ \\
\hline $\mathrm{F}$ & 2 & $0.11^{*}$ & $0.003 \mathrm{~ns}$ & $0.035^{*}$ \\
\hline $\mathrm{S}^{*} \mathrm{I}$ & 2 & $0.14^{*}$ & $0.006^{*}$ & $0.003^{\mathrm{ns}}$ \\
\hline $\mathrm{S}^{*} \mathrm{~F}$ & 2 & $0.09 \mathrm{~ns}$ & $0.003^{\mathrm{ns}}$ & $0.017 \mathrm{~ns}$ \\
\hline $\mathrm{I}^{*} \mathrm{~F}$ & 4 & $0.47^{* *}$ & $0.013^{* *}$ & $0.001 \mathrm{~ns}$ \\
\hline $\mathrm{S}^{*} \mathrm{I}^{*} \mathrm{~F}$ & 4 & $1.05^{* *}$ & $0.035^{* *}$ & $0.007 \mathrm{~ns}$ \\
\hline Error & 36 & 0.03 & 0.001 & 0.008 \\
\hline
\end{tabular}

${ }^{* *}, *$ and ns indicate significant at the $0.01,0.05$ probability levels and not significant respectively.

Table 7. Comparing means of interactions water use efficiency

\begin{tabular}{|c|c|c|c|c|c|}
\hline \multicolumn{3}{|c|}{ Treatments } & $W U E_{\text {wet }}$ & $W U E_{d t y}$ & $W U E_{\text {sced }}$ \\
\hline \multirow{9}{*}{$\mathrm{S}_{1}$} & \multirow{3}{*}{$\mathrm{I}_{1}$} & $\mathrm{~F}_{1}$ & 0.69 def & 0.11 def & $0.33 a$ \\
\hline & & $\mathrm{F}_{2}$ & 0.76 def & 0.13 def & 0.33 a \\
\hline & & $\mathrm{F}_{3}$ & 0.82 cdef & 0.14 def & $0.29 a$ \\
\hline & \multirow{3}{*}{$\mathrm{I}_{2}$} & $\mathrm{~F}_{1}$ & 0.73 def & 0.13 def & $0.33 a$ \\
\hline & & $\mathrm{F}_{2}$ & 0.58 ef & 0.09 ef & $0.37 \mathrm{a}$ \\
\hline & & $\mathrm{F}_{3}$ & $1.32 \mathrm{bc}$ & $0.25 \mathrm{bc}$ & $0.21^{\mathrm{a}}$ \\
\hline & \multirow{3}{*}{$\mathrm{I}_{3}$} & $\mathrm{~F}_{1}$ & 0.70 def & 0.13 def & $0.22 \mathrm{a}$ \\
\hline & & $\mathrm{F}_{2}$ & 0.84 cdef & 0.16 cde & $0.28^{a}$ \\
\hline & & $\mathrm{F}_{3}$ & 0.76 def & 0.13 def & $0.23 \mathrm{a}$ \\
\hline \multirow{9}{*}{$\mathrm{S}_{2}$} & \multirow{3}{*}{$\mathrm{I}_{1}$} & $\mathrm{~F}_{1}$ & $1.18 \mathrm{bcd}$ & $0.20 \mathrm{bcd}$ & $0.35 \mathrm{a}$ \\
\hline & & $\mathrm{F}_{2}$ & 0.94 cde & 0.15 cdef & $0.28 \mathrm{a}$ \\
\hline & & $\mathrm{F}_{3}$ & $0.34^{\mathrm{f}}$ & $0.05^{f}$ & $0.16^{a}$ \\
\hline & \multirow{3}{*}{$\mathrm{I}_{2}$} & $\mathrm{~F}_{1}$ & $1.13 \mathrm{bcd}$ & $0.20 \mathrm{bcd}$ & $0.30^{a}$ \\
\hline & & $\mathrm{F}_{2}$ & $1.65 \mathrm{ab}$ & $0.29 \mathrm{ab}$ & $0.22 \mathrm{a}$ \\
\hline & & $\mathrm{F}_{3}$ & 0.84 cdef & 0.15 cdef & $0.22 \mathrm{a}$ \\
\hline & \multirow{3}{*}{$\mathrm{I}_{3}$} & $\mathrm{~F}_{1}$ & 0.83 cdef & 0.15 cdef & $0.32 \mathrm{a}$ \\
\hline & & $\mathrm{F}_{2}$ & 0.84 cdef & 0.15 def & $0.22 \mathrm{a}$ \\
\hline & & $\mathrm{F}_{3}$ & $2.06^{a}$ & $0.37 \mathrm{a}$ & $0.19 \mathrm{a}$ \\
\hline
\end{tabular}

Means within each column followed by the same letter are not statistically different at $\mathrm{a}=0.05$ by LSD test. 
use efficiency was achieved in the $\mathrm{S}_{2} \mathrm{I}_{3} \mathrm{~F}_{3}$ treatment with the amount of 2.06 $\mathrm{kg} / \mathrm{m}^{3}$, while the least water use efficiency was seen in the $\mathrm{S}_{1} \mathrm{I}_{1} \mathrm{~F}_{3}(0.34$ $\mathrm{kg} / \mathrm{m}^{3}$ ) treatment. ANOVA results of water use efficiency in terms of dry leaves of basil yield $\left(W U E_{d r y}\right)$ show that irrigation, soil texture and triple interactions have a significant effect (at the 0.01 level|) on water use efficiency, while the nano fertilizer treatments were not significant. Also, comparison of mean values of the effects of three treatments on WUE $\mathrm{Wry}_{\mathrm{f}}$ (Table 7) showed that the highest mean efficiency (0.37) was achieved in the $\mathrm{S}_{2} \mathrm{I}_{3} \mathrm{~F}_{3}$ treatment, while the lowest water use efficiency $(0.05)$ was in the $\mathrm{S}_{2} \mathrm{I}_{1} \mathrm{~F}_{3}$ treatment.

Also ANOVA results on water use efficiency based on basil seed yield $\left(W U E_{\text {seed }}\right)$ show that only the nano fertilizer $(\mathrm{F})$ treatment has a significant effect on water use efficiency, becoming significant at 0.05 level. Given that the triple effect on $W_{U E}$ seed has not become significant, thus, all the treatments were considered at a same level.

In this research, the highest fresh and dry leaves yields in full irrigation treatment $\left(\mathrm{F}_{1} \mathrm{I}_{1} \mathrm{~S}_{2}\right)$ were obtained as 0.33 and $0.063 \mathrm{~kg} / \mathrm{m}^{2}$, while the highest average water use efficiency was achieved in deficit irrigation treatment. The results on simple effects of average water use efficiency are shown in Figure 3.

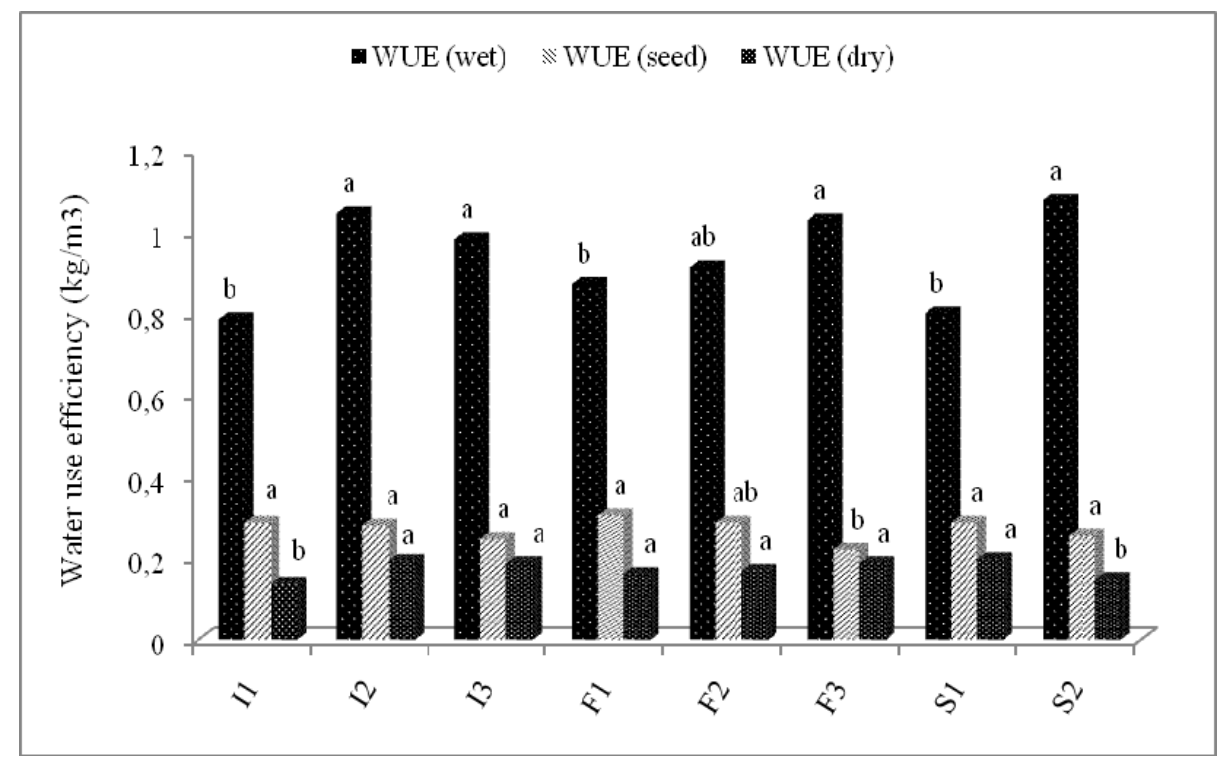

Figure 3. Average water use efficiency (WUE) in the triple treatments *Mean comparison for each type of WUE was done by LSD test at $p<0.05$ 


\subsection{Yield response factor $\left(k_{y}\right)$}

The relative reduction factors $\left(k_{y}\right)$ influenced by the reducing crop evapotranspiration is under water stress that is provided for basil in Table 8.

Generally, $k_{y}$ is lower under water stress in growth period, and higher in flowering periods and seed formation. Crop stress sensitivity coefficient in the second year is higher than the first year so that the values of the first and second culture years are as 1.35 and 1.82, respectively.

Table 8. The mean of $\mathrm{k}_{\mathrm{y}}$ during crop growth stage under water stress

\begin{tabular}{|c|c|c|c|}
\hline & $1-E T_{a} / E T_{m}$ & $1-Y_{a} \Upsilon_{m}$ & $k_{y}$ \\
\hline The first year & 0.47 & 0.63 & 1.35 \\
\hline The second year & 0.28 & 0.44 & 1.82 \\
\hline
\end{tabular}

\subsection{Determining of yield and cost function}

English et al. (1990) model was used for optimizing irrigation depth. For the calculation of the optimal depth index, the model needs to determine the used water-yield and used water-cost functions. As mentioned, the average water depth and yield data at different levels of water irrigation depth in the first and second years of culture were used and the best mathematical functions were obtained, which results are presented in Table 9.

The results showed that water balance model has a determination coefficient $\left(\mathrm{R}^{2}=0.85\right)$ better than the REC-P55 and pan evaporation models.

Table 9. Results of yield and cost functions

\begin{tabular}{|c|c|l|c|}
\hline $\begin{array}{c}\text { Method of calculation } \\
\text { irrigation depth }\end{array}$ & $\begin{array}{c}\text { Water irrigation function- } \\
\text { cost }\end{array}$ & \multicolumn{1}{|c|}{$\mathrm{R}^{2}$} & $\begin{array}{c}\text { Water irrigation } \\
\text { function-yield }\end{array}$ \\
\hline Pan evaporation & ${ }^{*} \mathrm{C}(\mathrm{w})=85000 \mathrm{w}+10000000$ & 0.82 & $\begin{array}{c}\mathrm{Y}(\mathrm{w})=- \\
{ }^{*} 2.866 \mathrm{w}^{2}+428.92 \mathrm{w}-1022\end{array}$ \\
\hline Water balance & $\mathrm{C}(\mathrm{w})=85000 \mathrm{w}+10000000$ & 0.85 & $\begin{array}{c}\mathrm{Y}(\mathrm{w})-2.2302 \mathrm{w}^{2}+ \\
303.85 \mathrm{w}-4437.9\end{array}$ \\
\hline REC-P55 & $\mathrm{C}(\mathrm{w})=85000 \mathrm{w}+10000000$ & 0.83 & $\begin{array}{c}\mathrm{Y}(\mathrm{w})=-1.9973 \mathrm{w}^{2}+ \\
267.18 \mathrm{w}-3042.2\end{array}$ \\
\hline
\end{tabular}

$\mathrm{Y}^{*}$ : is equal to the basil yield in $\mathrm{Kg} / \mathrm{ha}, \mathrm{W}$ : water consumed depth in $\mathrm{cm}, \mathrm{C}$ : the cost function in Rials 


\subsection{Optimal depth index}

Water depth under land limitations $\left(W_{l}\right)$, depth of water under limited water conditions $\left(W_{w}\right)$, maximum water depth equivalent $\left(\mathrm{W}_{\mathrm{el}}\right)$ and maximum depth of water used $\left(W_{m}\right)$ were calculated according to the presented model by English (1990) as well as production and cost functions, which results are presented in Table 10. Due to basil deficit irrigation compared to the maximum irrigation, some water is saved, based on which, a new area can be cultivated to increase the total yield, leading finally to increased income. The results show that the maximum water depth for basil is $74.82 \mathrm{~cm}$ by pan method. The water depth can be saved as $9.52 \mathrm{~cm}$ to increase the cultivation area as $0.13 \mathrm{ha}$, while in the water balance method, the cultivation area can be increased as 0.21 ha.

Due to the increasing cultivated area in deficit irrigation, there is the possibility of increasing cultivation area for limited water conditions as approximately $20 \%$ for basil compared to the maximum irrigation method. Therefore, in identical circumstances and in the case of no land constraints, more profits could be made. Economic analysis of costs and benefits are provided for basil in Table 11. The results show that the maximum efficiency per cubic meter of water is as 1849 Rials in a state of water limits for basil plant.

Table 10. Results of the optimal irrigation depths of basil

\begin{tabular}{|c|c|c|c|c|}
\hline $\begin{array}{c}\text { Method of } \\
\text { calculation } \\
\text { irrigation depth }\end{array}$ & $\begin{array}{c}\text { Land- } \\
\text { limiting } \\
(\mathrm{cm})\end{array}$ & $\begin{array}{c}\text { Water- } \\
\text { limiting } \\
(\mathrm{cm})\end{array}$ & $\begin{array}{c}\text { Maximum water } \\
\text { depth } \\
(\mathrm{cm})\end{array}$ & $\begin{array}{c}\text { Water } \\
\text { depth } \\
\text { saving } \\
(\mathrm{cm})\end{array}$ \\
\hline Pan evaporation & 71.86 & 65.30 & 74.82 & 9.52 \\
\hline Water balance & 64.32 & 53.73 & 68.12 & 14.39 \\
\hline REC-P55 & 62.64 & 50.24 & 66.89 & 16.64 \\
\hline
\end{tabular}

Table 11. Results of economic analysis and the benefits and costs by English (1990) method

\begin{tabular}{|c|c|c|c|c|}
\hline $\begin{array}{c}\text { Method of calculation } \\
\text { irrigation depth }\end{array}$ & $\begin{array}{c}\text { Total revenue } \\
(\text { Rial })\end{array}$ & $\begin{array}{c}\text { Total cost } \\
\text { (Rial) }\end{array}$ & $\begin{array}{c}\text { Net profit } \\
\text { (Rial) }\end{array}$ & $\begin{array}{c}\text { Earnings per } \\
\text { cubic meter of } \\
\text { water (Rial) }\end{array}$ \\
\hline Pan evaporation & 31828653 & 16383792 & 15444861 & 1720 \\
\hline Water balance & 34201067 & 17598092 & 16602975 & 1849 \\
\hline REC-P55 & 35260493 & 18141909 & 17118584 & 1907 \\
\hline
\end{tabular}




\section{Discussion}

The results of the daily actual basil evapotranspiration on water balance method showed that the highest evapotranspiration was obtained as 9.6 $\mathrm{mm}$ after 83 days of cultivation in August. The results of daily basil evapotranspiration using the REC-P55 also showed that the maximum evapotranspiration measured using the device was as $12.7 \mathrm{~mm}$ after 63 days of the culture in July. The average evapotranspiration measured by the device was $3.83 \mathrm{~mm}$ at the beginning of the growing season, which has increased to $8.60 \mathrm{~mm}$ by increasing the cultivation period in the middle period. The measured single crop coefficient compared to the crop coefficient proposed by FAO-56 represents an acceptable proximity between the measured and suggestions values. The FAO recommended value is $15 \%$ lower than the measured value in the third period.

The highest water use efficiency (WUE) was achieved in terms of fresh and dry yields as 2.06 and $0.37 \mathrm{~kg} / \mathrm{m}^{3}$ in the $\mathrm{S}_{2} \mathrm{I}_{3} \mathrm{~F}_{3}$ treatment, respectively. While the highest water use efficiency in terms of seed yield was achieved in the $\mathrm{S}_{1} \mathrm{I}_{2} \mathrm{~F}_{2}\left(0.37 \mathrm{~kg} / \mathrm{m}^{3}\right)$ treatment. The $k_{y}$ under water stress was achieved in the first and second culture years as 1.35 and 1.82, respectively, indicating the basil sensitivity to water stress.

The results of Benli and Kodal (2003) showed in some capacity levels, with the non-linear programming (NLP) model, instead of two different irrigation volume applications for one crop, the best irrigation volume ratio has been calculated.

The water-yield and water-cost functions for basil were obtained. Then, the water consumption depth under land limitations $\left(W_{l}\right)$, the depth of water use under limited water conditions $\left(W_{w}\right)$, the maximum water depth equivalent $\left(\mathrm{W}_{\mathrm{el}}\right)$ and the maximum depth of water use $\left(\mathrm{W}_{\mathrm{m}}\right)$ were calculated according to the model presented by English (1990) as well as production and cost functions. Also, the results on water depth optimization showed that the maximum irrigation depth for basil is $68.12 \mathrm{~cm}$, of which $14.39 \mathrm{~cm}$ can be saved to increase the cultivation area as 0.21 hectares, or to use this amount of water for water resources storage.

Finally, the efficiency for water consumption per cubic meter was obtained as 1849 Rials. 


\section{References}

[1] Allen RG, Pereira LS, Raes D, Smith M. 1998. Crop evapotranspiration: Guidelines for computing crop water requirements. FAO Irrigation and drainage paper 56300 : $1-15$.

[2] Abedi-Koupai J, Eslamian SS, Zareian MJ. 2011. Measurement and modeling of water requirement and crop coefficient for cucumber, tomato and pepper using microlysimeter in greenhouse. Journal of Science and Technology of Greenhouse Culture 2: 51-64.

[3] Ansari H, Salarian M, Takarli A, Bayram M. 2014. Determining Optimum Irrigation Depth for Wheat and Tomato Crops Using Aquacrop Model (A case study in Mashhad). Iiranian Journal of Irrigation and Drainage 8: 86-95.

[4] Bettaieb I, Zakhama N, Wannes WA, Kchouk ME, Marzouk B. 2009. Water deficit effect on Salvia officinalis fatty acids and essential oils composition. Scientia Horticulturae 120: 271-275.

[5] Benli, B., Kodal, S. 2003. A non-linear model for farm optimization with adequate and limited water supplies: application to the South-east Anatolian Project (GAP) Region. Agricultural water management, 62(3), 187-203.

[6] Chatrnoor M, Rasoulzadeh A, Rahmaniyan M, Esmaeel pur B, AbdulPur A. 2011. Measuring water requirement and basil crop coefficient in Ardabil. The sixth national conference on new ideas in agriculture. Khorasgan. Islamic Azad University of Isfahan (Khorasgan branch).

[7] De Souza CR, Maroco JP, Dos Santos TP, Rodrigues M, Lopes CM, Pereira J, Chaves MM. 2005. Impact of Deficit Irrigation on Water Use Efficiency and Carbon Isotope Composition (Delta C-13) . of Field-Grown Grapevines under Mediterranean Climate. Journal of Experimental Botany 56: 2163-2172.

[8] Doorenbos J, Kassam AH. 1979. Yield response to water. Room: Food and Agriculture Organization of the United Nations. Irrigation and Drainage 33: 193.

[9] Ekren S, Sonmez C, Ozcakal E, Kurttas YSK, Bayram E, Gurgulu H. 2012. The effect of different irrigation water levels on yield and quality characteristics of purple basil (Ocimum basilicum L.). Agricultural water management 109: 155-161.

[10] English M, Raja SN. 1996. Perspectives on deficit irrigation. Agricultural Water Management 32: 1-14.

[11] English M. 1990. Deficit irrigation. I: Analytical framework. Journal of Irrigation and Drainage engineering 116: 399-412.

[12] English MJ, Musick JT, Murty VVN. 1990. Deficit irrigation. In: Management of farm irrigation systems. American Society of Agricultural Engineers publisher 9: 1020.

[13] Fereres E, Soriano M. 2007. Deficit Irrigation for Reducing Agricultural Water Use. Journal of Experimental Botany 58: 147-159.

[14] García-Vila M, Fereres E. 2012. Combining the simulation crop model AquaCrop with an economic model for the optimization of irrigation management at farm level, In European Journal of Agronomy, 36(1): 21-31.

[15] Hassan FAS, Ali EF. 2014. Impact of different water regimes based on class-A pan on growth, yield and oil content of Coriandrum sativum L. plant. Journal of the Saudi Society of Agricultural Sciences 13: 155-161. 
[16] Khalid, A. 2006. Influence of Water Stress on Growth, Essential Oil, and Chemical Composition of Herbs (Ocimum Sp.). International Agrophysics 20: 289-296.

[17] Omobolanle Ade-Ademilua E, Oghenekome Obi H, Craker LE. 2013. Growth and Essential Oil Yield of African Basil, Ocimum gratissimum, under Light and Water Stress. Journal of Medicinally Active Plants 1: 5.

[18] Tavakoli AL, Moghadam MM. 2012. Optimization of deficit irrigation and nitrogen rates on bread irrigated wheat at northwest of iran. International Journal of Agriculture and Crop Sciences 4: 1681-1687.

[19] Unlu M, Kanber R, Koc DL, Tekin S, Kapur B. 2011. Effect of deficit irrigation on the yield components of drip irrigated cotton in a Mediterranean environment Agricultural Water Management 98: 597-605 